vol.4 No.1 - 2017

\title{
AUTISTIC SYMPTOMS AND ADAPTIVE BEHAVIOR AMONG EGYPTIAN CHILDREN WITH AUTISM SPECTRUM DISORDER. \\ ${ }^{1}$ Mohamed Ali A. Zoromba, ${ }^{2}$ Sayeda Ahmed Abdellatif \& \\ ${ }^{3}$ Osama Ahmed El-Boraie \\ 1 A. lecturer of Psychiatric and mental health Nursing, Faculty of Nursing, Mansoura University, \\ 2 Professor of Psychiatric and mental health Nursing, Faculty of Nursing, Cairo University, 3 Professor of Psychiatry, Faculty of Medicine, Mansoura University. E-mail of the corresponding author: zromba2010@mans.edu.eg
}

Abstract

Present study aims to assess the severity of autistic symptoms and adaptive behavior and the relationship between the two variables among Egyptian sample of children with Autism Spectrum disorder (ASD). A descriptive study was utilized with a sample of (28) children diagnosed with ASD by a consultant psychiatrist at "Maharaty center" in "Alzhour Association for community development". It's a governmental association affiliated to the Ministry of Social Affairs. Data collected using three tools, one for assessing socioeconomic status scale for health research in Egypt, the second for assessing the severity of autistic symptoms using Gilliam Autism Rating Scale (GARS), and the third for assessing adaptive behavior using Vinland Adaptive Behavior Scale (VABS). Results reveals that the severity of autistic symptoms correlate significantly and negatively with communication, daily living skills and social behavior where no significant relation between severity of autistic symptoms and motor skills. In conclusion, there is a significant negative relationship between severity of autistic symptoms and adaptive behavior. Therefore, it is recommended for nurses to enhance adequate training about adaptive behavior for those children to minimize their dependence and disability.

Keywords: Autistic symptoms, adaptive behavior, Egyptian children and autism spectrum

\section{Introduction:} disorder

Leo Kanner was the person who got the talent of being able to step back and see the whole picture when he published his initial paper in 1943 about autistic disturbances of affective contact. Before this time, children with autism were diagnosed with childhood onset schizophrenia. Kanner recognized several differential characteristics of some children which made them different from those with schizophrenia. He identified the disorder of this group of children as "autistic disturbances" and proposed a new diagnostic category. From the nearly 80 years after Kanner's first description of autistic disorder (autism), we have seen this diagnosis develop considerably (1).

Autism spectrum disorder (ASD) is a biological based neuro-developmental disorder; characterized by deteriorations in two major domains: a. deficits in social interaction and communication and $b$. restricted stereotyped repetitive patterns of interests, behaviors, and activities. ASD covers disorders known, previously, as autistic disorder (classic autism, sometimes called childhood autism, early infantile autism, or Kanner's autism), pervasive developmental disorder-not otherwise specified, childhood disintegrative disorder, and Asperger disorder (also known as Asperger syndrome) if the current diagnostic criteria are met (2).

In Egypt about 800,000 child with autism. In 2014, center of disease control (CDC) published that about 1 in 68 children has been identified with ASD according to estimates from CDC's Autism and Developmental Disabilities 
Monitoring (ADDM) Network. ASD is reported to occur in all ethnic, racial, and socioeconomic groups. Studies in North America, Europe, and Asia have identified individuals with ASD with an average prevalence of about $1 \%$. A study in South Korea demonstrated a prevalence of $2.6 \%$ (3).

A relative or total absence of reciprocal social interactive skills is the primary symptom seen in children with autism spectrum disorder. These children make less frequent eye contact and direct fewer facial expressions toward their parents. A significant problem with communication is another core symptom in children with ASD. Preschoolers diagnosed with autism may demonstrate delays in spoken language or may be completely nonverbal. They may simply echo what is said to them without meaning. Some children may be able to speak but demonstrate a lack of pragmatic communication skills (4).

In contrast to this negative symptoms, the other symptom of autistic spectrum disorders involves behavioral excess. Children with autism may engage in repetitive mannerisms, such as banging their hands, flicking their fingers in front of their eyes, pacing back and forth, running on tiptoe, and so on. Objects may be used in unusual ways, such as spinning or tapping them or repeatedly flicking a doll's eyes open and shut. Some children demonstrate an excessive interest in unusual topics. Children diagnosed with autism also may be rigid, insisting on following specific rituals, demanding to perform activities in an exact order, or following the same route to a destination. Repetitive actions sometimes evolve into self-injurious behaviors, such as headtaping, hand-biting, or face-slapping (4).

It is well documented that individuals with ASD experience impairments in adaptive behavior because of their intention to resist the change and to display stereotypical behaviors that interfere with acquiring key developmental tasks (5). Adaptive behavior refers to behaviors critical in every-day life in terms of Communication, Socialization, self-help and life skill s and independence (6).

Adaptive behavior is a multifaceted sit that includes skills necessary for age adequate independent living. The Vineland Adaptive Behavior Scales are the most commonly used measure of adaptive behavior and functioning in clinical and research contexts; it quantifies abilities in the domains of communication, daily living skills (DLS), socialization, and motor skills (7).

Individuals with ASD, have significant deteriorations in adaptive behaviors (8). Children early diagnosed with of autism commonly will not become completely independent as adults; many will need help in employment and residential living (9). The standard levels of adaptive functioning in children with ASD are seen to decline by the time (10). However, a significant minor ratio of persons with ASD, especially those with less severe symptoms and fluency of language skills by age five, will be able to perform the daily living activities and complete higher education (11).

A typical profile of adaptive skills in children with ASD, is marked by greatest delays in socialization with lesser delays in communication and relative strengths in daily living skills. Variance in adaptive behavior may go between by different cognitive levels to a certain scope. This reveals that persons with the spectrum are failing to acquire skills that are expected in relation to their chronological and cognitive development $(10,12)$. Deteriorations in adaptive behaviors were found even in every child with autism, which increased with increasing age (13).

Results of previous researchers studied the relations between adaptive behavior skills and autism symptoms have been 
AUTISTIC SYMPTOMS AND ADAPTIVE BEHAVIOR etc...

maladjusted. Some studies have presented a weak relation between autism severity of symptoms and adaptive behavior. Other studies have found a moderate to strong relation between adaptive behaviors and autism severity $(10,14)$.

The American Association on Mental Retardation (AAMR) defines adaptive behavior as "the collection of conceptual, social, and practical skills that have been learned by people in order to function in everyday lives" (15). Adaptive behavior is best understood as the degree to which individuals are able to function and maintain themselves in dependently and meet cultural expectations for personal and social responsibility at various ages. As such, adaptive behavior involves the person's cognitive ability, physical skills, affect, culture, motivation, socio-economic status, family, and environment (16).

The assessment of adaptive behavior according James (17) include the following four domains:

Communication dimension:

- Receptive: How the individual listens and give attention and what he or she understands.

- Expressive: What the individual says, how he or she speaks word and sentences to gather and present information.

- Written: What the individual understand about how letters make words, and what he or she read and write.

Daily living activities dimension:

- Personal: How the individual eats, dresses, and practices personal hygiene.

- Domestic: What household tasks the individual performs.

- Community: How the individual uses time, money, the telephone, the computer, and job skills.

Socialization dimension:

- Interpersonal Relationships: How the individual communicate with others.

- Play and Leisure Time: How the individual plays and utilize leisure time.
- Coping skills: How the individual takes responsibility and sensitivity to others.

\section{Motor Skills dimension:}

- Gross Motor: How the individual employs arms and legs for movement and coordination.

- Fine Motor: How the individual employs hands and fingers to manipulate objects.

Rising levels of the prevalence of ASD in children (about 800,000 children in Egypt) are a serious societal and economic problem. Therefore, the urgent need for concise assessment and identifying dimensions of this disorder to be able to participate in the implementation of adequate interventions is vital step to minimize the hazards of autism.

Aim of the study:

Assessing the severity of autistic symptoms and adaptive behavior and the relationship between the severity of autistic symptoms and adaptive behavior among Egyptian sample of children with Autism Spectrum disorder (ASD).

\section{Subjects and Method:-}

\section{Study Design:}

A descriptive cross sectional research design.

\section{Setting:}

This study was conducted at "Maharaty center" in "Alzhour Association for community development". The association affiliated to the Ministry of Social Affairs. It is located at Alzhour District in Port Said city, Egypt. Researcher do the study from the beginning of March 2015 to the end of June 2015.

\section{Subjects:}

Convenient sample of children consisted of all children with autism spectrum disorder who attend to the identified setting. They were 28 children (21 male and 7 female) and the diagnosis by a consultant psychiatrist as they are affected with Autism spectrum disorder according DSM-5 criteria and the diagnosis is confirmed by assessing the 
severity of ASD using the Arabic version of the Gilliam Autistic Rating Scale (GARS). Children mean age was $4.95 \pm$

.79 years.

Tools:

Three scales were used to collect data, which include the following:

Scale I: Socioeconomic status scale to address health research in Egypt. It has 7 domains with a total score of 84, they are Education and cultural, Family, Economic, Occupation, Family possessions, Home sanitation and Health care domains (18).

Scale II: Gilliam Autism Rating Scale (GARS), it is a 56 item for the assessment of individuals ages 3-22 who have major behavioral problems that may be indicator for autism. Main subscales are: stereotyped behaviors, communication, social interaction and developmental disturbances. It takes about 10-15 minutes. The Arabic version of scale is a highly standardized test designed to measure the severity of autistic symptoms. Internal consistency of the GARS was determined using Cronbach's alpha technique as .92 and coefficients alpha is .94 Scoring system of GARS follow the following: very low : less than or equal 69', low $70: 79$, below average "80:89", average "90:110", over average "111:120", high "121:130" and very high "more than 131"(19).

Scale III: Vinland Adaptive Behavior Scale (VABS), its measure an individual's adaptive level of functioning. Main subscales are: Communication, Daily Living Skills, Socialization and Motor Skills. Internal consistency of the Arabic version of VABS was determined using Cronbach's alpha technique which was .86 up to .97 in Arabic culture. Test retest revealed coefficients alpha from .7 to .99 . Scoring system of VABS follow the following: more than 130 equal high, 130:116 equal over average, 115:85 equal average, 70:84 equal less than average, 69:20 or less equal low (20).

Ethical consideration:

- The permission was obtained from the faculty of nursing ethics committee and from the director of the association.

- Verbal or informed consent of the children's caregivers was obtained.

\section{Statistical analysis:}

Data were analyzed with SPSS version 21. The normality of data was first tested with one-sample Shapiro-Wilk test.

Qualitative data were described using number and percent. Pearson correlation used for correlation between continuous parametric data while spearman correlation to correlate between continuous non- parametric data. The significance is fixed at 5\% level (p-value).

Results:

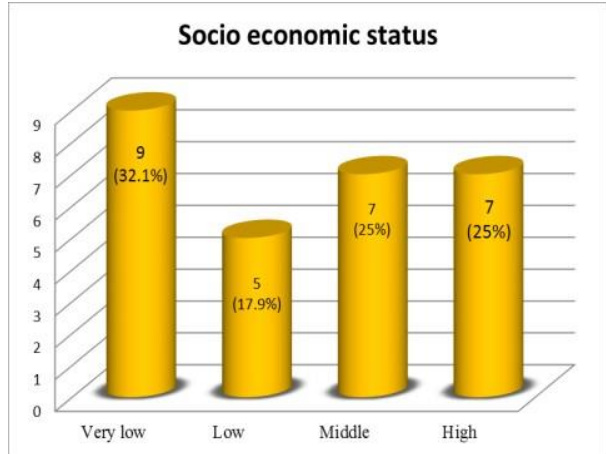

Figure (1) Socio-economic level of studied sample

Socio economic status of studied sample, according to the figure (1), there is about one third $(32.1 \%)$ of studied sample are very low socio-economically where one fourth is middle and another one fourth is high socio-economic status. 


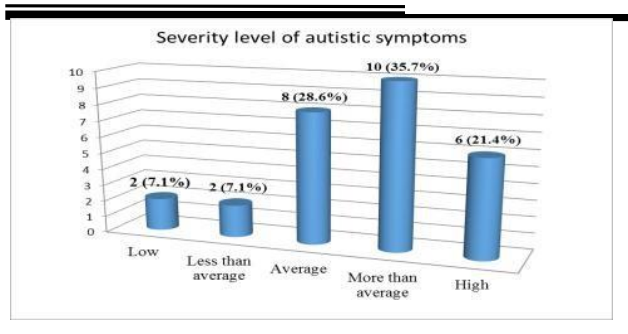

Figure (2): Frequencies of the severity

levels of autism subscales and total

severity levels of autistic symptoms.

According to figure (2), about one third $(35.7 \%)$ of the studied sample are more than average in their severity of autistic symptoms, $(28.6 \%)$ and $(21.4 \%)$ of them with average and high severity of autistic symptoms.

Table (1): Frequencies of the levels adaptive behavior subscales and total adaptive behavior.

\begin{tabular}{|c|c|c|c|c|c|c|c|c|c|c|}
\hline & \multicolumn{2}{|c|}{ Communication } & \multicolumn{2}{|c|}{ D L A } & \multicolumn{2}{c|}{ Social } & \multicolumn{2}{c|}{ Motor } & \multicolumn{2}{c|}{ Total } \\
\cline { 2 - 12 } & $\mathbf{N}$ & $\mathbf{\%}$ & $\mathbf{N}$ & $\mathbf{\%}$ & $\mathbf{N}$ & $\mathbf{\%}$ & $\mathbf{N}$ & $\mathbf{\%}$ & $\mathbf{N}$ & $\%$ \\
\hline Average & 1 & 3.6 & 3 & 10.2 & 2 & 7.1 & 4 & 14.3 & 2 & 7.1 \\
\hline $\begin{array}{c}\text { Less than } \\
\text { Average }\end{array}$ & 1 & 3.6 & 6 & 21.4 & 4 & 14.3 & 4 & 14.3 & 1 & 3.6 \\
\hline $\begin{array}{c}\text { Mild } \\
\text { impairmen } \\
\text { t }\end{array}$ & 3 & 10.7 & 1 & 46.4 & 15 & 53.6 & 4 & 14.3 & 6 & 21.4 \\
\hline $\begin{array}{c}\text { Moderate } \\
\text { impairment }\end{array}$ & 5 & 17.9 & 5 & 17.9 & 7 & 25 & 11 & 39.3 & 15 & 53.6 \\
\hline $\begin{array}{c}\text { Severe } \\
\text { impairmen } \\
\text { t }\end{array}$ & 10 & 35.7 & 1 & 3.6 & - & - & 3 & 10.7 & 4 & 14.3 \\
\hline $\begin{array}{c}\text { Profound } \\
\text { impairment }\end{array}$ & 8 & 28.6 & - & - & - & - & 2 & 7.1 & - & - \\
\hline
\end{tabular}

Frequencies of the levels of adaptive behavior domains and total of levels of adaptive behavior are illustrated in table (1), according to the table, more than of one third of studied sample $(35.7 \%)$ and $(28.6 \%)$ have a severe and profound impairment, respectively, in their communication. About half of studied sample have a mild impairment in daily living activity behavior and social behavior. Two fifth $(39.3 \%)$ of studied sample have a moderate impairment in motor functioning. Generally more than half of studied sample have a moderate impairment in their level of adaptive behavior. This impairment related to the impairment in the communication, motor behavior, daily living behavior and social behavior respectively.
Table (2): Socio economic status subscales in relation to adaptive behavior and severity of autistic symptoms.

\begin{tabular}{|l|c|c|c|c|}
\hline \multirow{2}{*}{\multicolumn{1}{|c}{ SES }} & \multicolumn{2}{|c|}{ GARS } & \multicolumn{2}{c|}{ VABS } \\
\cline { 2 - 5 } & $\mathbf{R}$ & $\mathbf{P}$ & $\mathbf{R}$ & $\mathbf{P}$ \\
\hline $\begin{array}{l}\text { Education } \\
\text { \& cultural }\end{array}$ & -.027 & .893 & .138 & .484 \\
\hline Occupation & -.303 & .117 & .267 & .170 \\
\hline Family & -.113 & .566 & - & .759 \\
\hline $\begin{array}{l}\text { Family } \\
\text { possessions }\end{array}$ & -.172 & .383 & .129 & .512 \\
\hline Economic & -.179 & .362 & .083 & .674 \\
\hline $\begin{array}{l}\text { Home } \\
\text { sanitation }\end{array}$ & -.143 & .467 & .05 & .799 \\
\hline Health care & -.309 & .11 & $\mathbf{. 4 3 5}$ & $\mathbf{. 0 2 1}$ \\
\hline
\end{tabular}

According to table (2), there is no significant relation between severity of 
autistic symptoms and all the seven domains of socio economic status. Total adaptive behavior of studied children isn't related significantly to education,

Table (3): Socio economic status in relation to Autism subscales and Adaptive behavior subscales.

\begin{tabular}{|c|c|c|c|c|c|}
\hline \multirow{2}{*}{ GARS } & \multicolumn{2}{|c|}{ SES } & \multirow{2}{*}{ VABS } & \multicolumn{2}{c|}{ SES } \\
\cline { 2 - 3 } \cline { 5 - 6 } & $\mathbf{r}$ & $\mathbf{P}$ & & $\mathbf{R}$ & P \\
\hline Stereotyped behavior & -.150 & .447 & Communication & .096 & .628 \\
\hline Communication & -.087 & .659 & DLA & .11 & .578 \\
\hline Social interaction & -.209 & .286 & Social Behavior & .028 & .887 \\
\hline Development disturbances & .235 & .228 & Motor & .167 & .395 \\
\hline
\end{tabular}

According to table (3), socio economic status neither correlate significantly with domains of autism rating scale nor domains of adaptive behavior scale.

Table (4): Adaptive behavior in relation to severity of autism subscales.

\begin{tabular}{|c|c|c|}
\hline \multirow{2}{*}{ GARS } & \multicolumn{2}{|c|}{ VABS } \\
\cline { 2 - 3 } & $\mathbf{R}$ & $\mathbf{P}$ \\
\hline Stereotyped behavior & -.613 & .001 \\
\hline Communication & -.457 & .003 \\
\hline Social interaction & -.366 & .055 \\
\hline $\begin{array}{c}\text { Development } \\
\text { disturbances }\end{array}$ & -.217 & .268 \\
\hline
\end{tabular}

Adaptive behavior and its relation to subscales of autism rating scale is presented in table (4), according to the table, adaptive behavior relates significantly and negatively to stereotyped behavior and communication. Although there is a negative direction between occupation, family, family possessions, economic and home sanitation domains but related significantly to health care adaptive behavior and social interaction but this direction doesn't reach to the level of significant relationship.

Table (5): Severity autistic symptoms in relation to Adaptive behavior subscales.

\begin{tabular}{|c|c|c|}
\hline \multirow{2}{*}{ VABS } & \multicolumn{2}{|c|}{ GARS } \\
\cline { 2 - 3 } & $\mathbf{R}$ & $\mathbf{P}$ \\
\hline Communication & -.453 & .016 \\
\hline DLA & -.602 & .001 \\
\hline Social Behavior & -.559 & .002 \\
\hline Motor & -.365 & .056 \\
\hline
\end{tabular}

Severity of autism and it relation to subscales of adaptive behavior is showed in table (5), according to the table, severity of autism relates significantly and negatively to communication, daily living activities behavior and social behavior but not reach to level of significance in relation to motor behavior.

Table (6): Relations between total score of studied variables.

\begin{tabular}{|c|c|c|c|c|c|c|}
\hline \multirow{2}{*}{ SES } & \multicolumn{2}{|c|}{ VABS } & \multicolumn{2}{c|}{ Adaptive age } & \multicolumn{2}{c|}{ GARS } \\
\cline { 2 - 7 } & $\mathbf{r}$ & $\mathbf{P}$ & $\mathbf{r}$ & $\mathbf{P}$ & $\mathbf{R}$ & $\mathbf{P}$ \\
\hline VABS & .122 & .537 & .024 & .905 & -.158 & .422 \\
\hline Adaptive age & & & .68 & .000 & -.59 & .001 \\
\hline
\end{tabular}

According to table (6), there is no significant relation between total socio economic status and adaptive behavior, equivalent adaptive age and severity of autism. Adaptive behavior relates significantly to equivalent adaptive age. Finally, severity of autism relates significantly and negatively to equivalent adaptive age and adaptive behavior.

\section{Discussion:}

Biological profile (gender) of studied children demonstrate a male predominance that the ratio is $3: 1$. This is congruent with the most date of literature. In the first 
publication about autism kanner (1943) mentioned that there was a male predominance as four times as females (21). Shu, Lung \& Change mentioned that ASD is more than twice common in boys, and the ratio increases to 5:1 (22). In a survey of 564 autistic patients, researchers found that 461 of them $(81 \%)$ were male (23). CDC mentioned that ASD is almost 5 times more common among boys (3). In Arabic countries, Amr et al., mentioned a matched ratio in Saudi Arabia but it different with data from Egypt and Jordan(24).

This finding support the biological influence of genetics in developing autism; the gene or genes of autism may be located on the $\mathrm{X}$ chromosome. Girls generally have more developed social skills they have the ability to mimic socially appropriate behavior than their male counterparts. Another point of view in which female less diagnosis with autism especially if they have a mild or moderate level of autistic symptoms as female may have little care than males.

Socio-economic status of studied children doesn't relate significantly to severity of autistic symptoms. Although one third of those children belonging to families who are very low socio economically. Also, half of studied sample are low and very low in their socioeconomic status. Current results congruent with other results in Arabic world mentioned by Amr et al., who stated that "Most of the children diagnosed with autism belonged to families of low socioeconomic standards with unsatisfactory income" (24). This results incongruent with results by El-Baz et al., who revealed that half of autistic children were of high socio-economic status (23). Kanner's impression that that autism relates to families with high socioeconomic status has proven to be incorrect early by study of schopler, Reichler, Devellis et al, (25). Individuals with ASD are found in all cultures, ethnicities, and across socioeconomic levels.

A relatively high percentage $(71.4 \%)$ of studied children are with average severity of autistic symptoms. One fifth of studied sample are high in their severity of symptoms. This is matched with study by El-Baz et al., in which mild autistic symptoms are lower than moderate and high (23). El-Baz et al., also found that a more than half of the sample were with severe autistic symptoms. Increasing the severity of autistic symptoms may be related to insufficient intervention provided to children with ASD in Egypt(23).

Current study also reveals a significant positive relation between total adaptive behavior and health care domain of socioeconomic status which indicate that the families who have a better usual source of care have a better adaptive behavior. That's may be related to the massive distance between care provided in private centers of intervention in contrast to governmental health service. Added to that the great costs of interventions provided to children with ASD.

Concerning adaptive profiles of studied children, about two thirds of studied children have a severe and profound impairment in their communication. About half of studied sample have a mild impairment in daily living activity behavior and social behavior. Two fifth of studied sample have a moderate impairment in motor functioning. Current results also reveal that the severity of autism relates significantly and negatively to communication, daily living activities behavior and social behavior but not reach to level of statistical significance in relation to motor behavior. Current results matched to studies of Sugar et al., Paul, Loomis \& Chawarska and Matthews et al., $(5,7,26)$. Kanne et al., found that the greatest impairments were observed in socialization skills, communication and 
Mohamed Ali A. Zoromba et. al.

daily living skills were moderately
delayed(27).

It is known that language delays are among the first symptoms that may intense parent and provider concern. Some individuals with ASD never evolve functional speech. Other show abnormal patterns, including pronoun reversal, idiosyncratic phrases, and immediate or delayed echolalia. Dependent on communication impairment; social behavior affected and impaired as the communication is the important engine for developing a well social interactive behavior. Daily living activities also affected but less than communication and socialization. Motor domain is the least affected domain as ASD is a mainly disorder of communication, socialization and restricted or repetitive behavior and the disorder within neurodevelopment not related mostly to motor development.

Adaptive behavior also, relates significantly and negatively to stereotyped behavior and communication. Although there is a negative direction between adaptive behavior and social interaction but this direction doesn't reach to a level of significant relationship. This finding is not matched to results by Watt, Wether by, Barber et al., who not found significant correlations between stereotyped behavior and adaptive behavior (28). Children with ASD with lower levels of adaptive behavior haven't the ability to control their all motor behaviors so that repetitive or restricted behavior affected. Communication and social interaction also are a domain in adaptive behavior in the same time they are a domain in autistic symptoms so that they are correlated.

Generally, more than half of studied sample have a moderate impairment in their level of adaptive behavior. This impairment related to the impairment in the communication, motor behavior, daily living behavior and social behavior respectively. There is a significant negative relation between severity of autistic symptoms and adaptive behavior and also equivalent adaptive age. Significant adaptive impairments were found in the individuals with ASD

This results matched the agreement mentioned within different studies like studies of Klin et al., and Kanne et al., who found associations between the level of autism symptomatology and adaptive behavior $(29,30)$. Also a studies of Perry et al., and Kenworthy et al., mentioned that autistic behavior ratings related negatively to adaptive behavior scale $(31,32)$.

This impairment may be related to impaired cognitive ability with children with ASD. It was known that $70 \%$ of children with ASD have mental retardation and this directly affect their skills of functioning. Current results support the change that adopted to the DSM-5 to address ASD according to the severity levels including; requiring support, requiring substantial support and requiring very substantial support. Decreased levels of adaptive behavior is considered as the primary consequences of autistic psychopathology.

Finding could have important partnership for intervention, particularly in the areas of communication, daily living activities, motor and social behavior. Therefore, it's recommended to use adaptive behavior assessment continuously to evaluate interventions provided to children with ASD is very important to address their progress. It's now clear that the main aim by dealing with children with ASD is to enhance their functioning and minimize their dependence and disability.

Limitation of current study was in the small size sample. As it's the convenient sample of all children available in the center and their caregivers accepted to participate in the study. In Egypt, more studies must be done to generalize current findings. Also multiple periodical assessment of those children to assess their 
AUTISTIC SYMPTOMS AND ADAPTIVE BEHAVIOR etc...

adaptive functioning is indicated to evaluate psychopathology of the disorder.

\section{References:}

1. Sadock B, Sadock V, Ruiz P. KAPLAN \& SADOCK'S Synopsis of Psychiatry Behavioral Sciences/Clinical Psychiatry [Internet]. Kaplan and Sadock's synopsis of psychiatry: Behavioral sciences/clinical psychiatry (11th ed.). 2015. p. 356-9.

2. American Psychiatric Association. Diagnostic and statistical manual of mental disorders. 5th ed. Arlington, VA: American Psychiatric Publishing; 2013. 991 p.

3. CDC. CDC estimates 1 in 68 children has been identified with autism spectrum disorder. 2014. Available from:

http://www.cdc.gov/media/releases/2 014/p0327-autism-spectrum-

disorder.html

4. Turkington C, Anan R. The Encyclopedia of Autism Spectrum Disorders. Childhood A Global Journal Of Child Research. 2007.

5. Sugar M, Konstantareas M, Rampton G. The adaptive profiles of individuals with autism spectrum disorder. J Dev Disabil. 2010;16(2):72-4.

6. Ashwood KL, Tye C, Azadi B, Cartwright S, Asherson P, Bolton P. Brief Report: Adaptive Functioning in Children with ASD, ADHD and ASD + ADHD. J Autism Dev Disord. United States; 2015 Jul;45(7):2235-42.

7. Matthews NL, Smith CJ, Pollard E, Ober-Reynolds S, Kirwan J, Malligo A. Adaptive Functioning in Autism Spectrum Disorder During the Transition to Adulthood. J Autism Dev Disord. United States; 2015 Aug;45(8):2349-60.

8. Howlin P, Goode S, Hutton J, Rutter M. Adult outcome for children with autism. J Child Psychol Psychiatry. Blackwell Publishing; 2004 Feb 1;45(2):212-29. Available from: http://dx.doi.org/10.1111/j.14697610.2004.00215.x

9. Moldin SO, Rubenstein JLR. Understanding Autism: From Basic Neuroscience to Treatment. CRC Press; 2006.

10. Buxbaum JD, Hof PR. The Neuroscience of Autism Spectrum Disorders. Elsevier/Academic Press; 2013. (Academic Press).

11. Kim SH, Lord C. The Behavioral Manifestations of Autism Spectrum Disorders. The Neuroscience of Autism Spectrum Disorders. Elsevier Inc.; 2013. 25-37 p. Available from: http://dx.doi.org/10.1016/B978-0-12391924-3.00002-8

12. Holtmann M, Bölte S. Poustka F:ADHD, Asperger syndrome, and high-functioning autism. J Am Acad Child Adolesc Psychiatry [Internet]. 2005;44. Available from: http://dx.doi.org/10.1097/01.chi.0000 177322.57931.2a

13. Anderson DK, Oti RS, Lord C, Welch K. Patterns Of Growth In Adaptive Social Abilities Among Children With Autism Spectrum Disorders. Vol. 37, Journal of abnormal child psychology. 2009. p. 1019-34.

14. Minshawi NF, Hurwitz S, Fodstad JC, Biebl S, Morriss DH, McDougle CJ. The association between selfinjurious behaviors and autism spectrum disorders. Psychol Res Behav Manag. 2014 Apr [cited 2017 May 1];7:125-36. Available from: http://www.dovepress.com/theassociation-between-self-injuriousbehaviors-and-autism-spectrum-dpeer-reviewed-article-PRBM

15. Matson JL, Glidden LM. International Review of Research in Mental Retardation: Handbook of 
Mohamed Ali A. Zoromba et. al.

Assessment in Persons with Intellectual Disability. Elsevier Science; 2007. (International Review of Research in Mental Retardation).

16. Cassidy A. Encyclopedia of Autism Spectrum Disorders. In: Volkmar FR, editor. New York, NY: Springer New York; 2013. p. 51. Available from: http://dx.doi.org/10.1007/978-14419-1698-3_1348

17. James A. Welcoming a New Brother or Sister Through Adoption. Jessica Kingsley Publishers; 2013.

18. El-Gilany A, El-Wehady A, ElWasify M. Updating and validation of the socioeconomic status scale for health research in Egypt. East Mediterr Health J. Egypt; 2012 Sep;18(9):962-8.

19. Mohamed A. Gilliam Autism Rating Scale Arabic version. Cairo: Dar Alrshad; 2006.

20. Aletibey B. Saudai Psychometric properties of Vinland Adaptive Behavior Scale. Spec Educ Acad. 2004;5.

21. Kanner L. Autistic Disturbances of Affective Contact. Nerv Child. 1943;2:217:250. Available from: http://neurodiversity.com/library_kan ner_1943.pdf

22. Shu BC, Lung FW, Chang YY. The mental health in mothers with autistic children: a case-control study in southern Taiwan. Kaohsiung J Med Sci. China (Republic : 1949- ); 2000 Jun;16(6):308-14.

23. El-Baz F, Ismael NA, El-Din SMN. Risk factors for autism: An Egyptian study. Egypt J Med Hum Genet. 2011 May;12(1):31-8. Available from:

http://www.sciencedirect.com/scienc e/article/pii/S1110863011000127

24. Amr $\mathrm{M}, \mathrm{Bu}$ Ali $\mathrm{W}$, Hablas $\mathrm{H}$, Raddad D, El-Mehesh F, El-Gilany $\mathrm{AH}$, et al. Sociodemographic factors in Arab children with Autism
Spectrum Disorders. Pan Afr Med J. 2012;13:65.

25. Schopler E, Reichler RJ, DeVellis RF, Daly K. Toward objective classification of childhood autism: Childhood Autism Rating Scale (CARS). J Autism Dev Disord. 1980;10(1):91-103. Available from: http://link.springer.com/10.1007/BF0 2408436

26. Paul R, Loomis R, Chawarska K. Adaptive behavior in toddlers under two with autism spectrum disorders. J Autism Dev Disord. United States; 2014 Feb;44(2):264-70.

27. Kanne SM, Gerber AJ, Quirmbach LM, Sparrow SS, Cicchetti D V., Saulnier CA. The role of adaptive behavior in autism spectrum disorders: Implications for functional outcome. J Autism Dev Disord. 2011;41(8):1007-18.

28. Watt N, Wetherby AM, Barber A, Morgan L. Repetitive and Stereotyped Behaviors in Children with Autism Spectrum Disorders in the Second Year of Life. Vol. 38, Journal of autism and developmental disorders. 2008. p. 1518-33.

29. Klin A, Saulnier CA, Sparrow SS, Cicchetti D V, Volkmar FR, Lord C. Social and Communication Abilities and Disabilities in Higher Functioning Individuals with Autism Spectrum Disorders: The Vineland and the ADOS. J Autism Dev Disord. 2006;37(4):748-59. Available from: http://dx.doi.org/10.1007/s10803006-0229-4

30. Kanne SM, Abbacchi AM, Constantino JN. Multi-informant Ratings of Psychiatric Symptom Severity in Children with Autism Spectrum Disorders: The Importance of Environmental Context. J Autism Dev Disord. 2009;39. Available from: http://dx.doi.org/10.1007/s10803- 
009-0694-7

31. Perry A, Flanagan HE, Dunn Geier J,

Freeman NL. Brief Report: The Vineland Adaptive Behavior Scales in Young Children with Autism Spectrum Disorders at Different Cognitive Levels. J Autism Dev Disord. 2009;39(7):1066-78. Available from: http://dx.doi.org/10.1007/s10803009-0704-9
32. Wallace GL, Kenworthy L, Pugliese CE, Popal HS, White EI, Brodsky E, et al. Real-World Executive Functions in Adults with Autism Spectrum Disorder: Profiles of Impairment and Associations with Adaptive Functioning and Co-morbid Anxiety and Depression. J Autism Dev Disord. NIH Public Access; 2016 Mar [cited 2017 Jan 16];46(3):1071-83. Available from: http://www.ncbi.nlm.nih.gov/pubmed 126572659 